\title{
Research productivity during orthopedic surgery residency correlates with pre-planned and protected research time: a survey of German-speaking countries
}

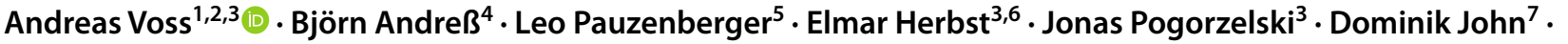 \\ Daniel Smolen ${ }^{8,9}$. Philip P. Roessler ${ }^{10}$. Daniel G. Tobert ${ }^{11}$. Jakob T. Sieker ${ }^{12,13}$ (D) For the Society of Arthroscopy and \\ Joint Surgery (AGA) Residents Forum, Research Working Group
}

Received: 6 November 2019 / Accepted: 6 April 2020 / Published online: 17 April 2020

(c) The Author(s) 2020

\begin{abstract}
Purpose The purpose of this study was to identify modifiable factors associated with research activity among residents working in orthopedic surgery and traumatology.

Methods Residents at 796 university-affiliated hospitals in Austria, Germany, and Switzerland were invited to participate. The online survey consisted of questions that ascertained 13 modifiable and 17 non-modifiable factors associated with the residents' current research activities. Responses of 129 residents were analyzed. Univariate linear regression was used to determine the association of individual factors with the current research activity (hours per week). The impact of significant non-modifiable factors (with unadjusted $p$ values $<0.05$ ) was controlled for using multivariate linear regression.

Results The univariate analysis demonstrated six non-modifiable factors that were significantly associated with the current research activity: a University hospital setting $(p<0.001)$, an A-level hospital setting $(p=0.024)$, Swiss residents $(p=0.0012)$, the completion of a dedicated research year $(p=0.007)$, female gender $(p=0.016)$, and the department's size $(p=0.048)$. Multivariate regression demonstrated that the number of protected research days per year $(p<0.029)$ and the percentage of protected days, that were known 1 week before $(p<0.001)$ or the day before $(p<0.001)$, were significantly associated with a higher research activity.

Conclusions As hypothesized, more frequent and predictable protected research days were associated with higher research activity among residents in orthopedic surgery and traumatology.

Level of evidence III.
\end{abstract}

Keywords Research · Orthopedic surgery training · Traumatology training · Residency

\section{Introduction}

Motivating and enabling residents to perform research during residency training is a challenge for program directors and department chairs [9]. The implementation of changes to resident curricula requires careful consideration from the program leadership. Often, objective data regarding the

Electronic supplementary material The online version of this article (https://doi.org/10.1007/s00167-020-05983-w) contains supplementary material, which is available to authorized users.

Andreas Voss

a.voss@tum.de

Extended author information available on the last page of the article potential ramifications of these changes are unavailable. In particular, there is a lack of knowledge on the consequences of such changes. Often, these changes are implemented on a trial and error basis.

Additionally, new working regulations within the European Union have forced employers to reduce, adapt, and control the workload of residents to $50 \mathrm{~h}$ per week (in many countries even $40 \mathrm{~h}$ per week). A reduced workload was enacted to enable residents with time for independent study, research and establish a healthy work-life balance. A similar regulation has been set in the United States in 2002 [7]. The clinical workload was reduced to maximum of $80 \mathrm{~h}$ per week. Analysis regarding resident's authorships significantly increased compared to the years before the workload regulation [7]. Also, the level of evidence of resident-authored 
papers has improved. Basic science papers were more likely to have a resident first author, indicating that clinical workload reduction had a positive influence on research output.

A study by Williams et al. [11] could demonstrate a significantly higher research output in American orthopedics residency programs with protected research time compared to programs without such dedicated time. This protected research time has often been touted as a solution to motivate trainee research. However, the addition of protected time for research necessarily decreases vital clinical time and experiences.

The aim of the current study was to identify modifiable factors that are associated with the current research activity of residents in orthopedic surgery and traumatology training programs across Europe. It was hypothesized that higher resident research activity is associated with the presence of faculty members who produce high-volume, meaningful research, the presence of robust research infrastructure and funding, as well as dedicated time for research.

\section{Materials and methods}

\section{Study design}

A cross-sectional, observational study was performed among residents enrolled in orthopedic surgery and traumatology residency programs across Austria, Switzerland and Germany during 2017. Using an online questionnaire, the resident physicians self-reported current research activity in hours per week, as well as responses for 13 modifiable and 17 non-modifiable factors (see Supplementary Table 1).

\section{Sample characteristics}

An online invitation for participation in the survey was sent to the chairs or program directors of all 796 orthopedic surgery and traumatology programs with university-affiliation across Austria, Germany and Switzerland. Those were subsequently asked to distribute the website address to the online questionnaire amongst their residents. All responses were recorded anonymously. A total of 146 residents completed the survey. Individuals older than 40 years $(N=13)$ of age were excluded, as they were deemed to not reflect the typical age range of orthopedic residents, which could influence their research activity (e.g. medicine as second career, family responsibilities). Individuals with more than $40 \mathrm{~h}$ per week of research $(N=4)$ were excluded as these respondents were presumed to be currently engaged in full-time research. Therefore, the responses of 129 residents were available for analysis.

When a resident responded that the longest duration of their training covered by one employment contract was
0 month then this entry was replaced by a missing value $(N=28)$. Contracts are expected to be at least 1 month of duration and, therefore, a response of 0 month was assumed to be erroneous. If respondents entered a percentage of protected days plannable the week before that was greater than the percentage plannable at least the day before, both entries were replaced by a missing value $(N=5)$, as at least one of the values was assumed to be erroneous. One response $(N=1)$ indicated that their institution was privately as well as government/community owned which was considered mutually exclusive and, therefore, both entries were replaced by a missing value. If a respondent indicated the faculty to resident ratio was $\leq 0$ or $\geq 5$ then the entries for department size, program size and faculty to resident ratio were replaced by missing values $(N=14)$. The faculty to resident ratio was calculated based on reported information on department size (that is number of residents and faculty combined) and program size (that is number of residents only). The number of faculty was calculated by subtracting the program size from the department size. If a respondent provided a department size smaller than the program size the calculated number of faculty and resulting faculty to resident ratio was less than 0 , which is implausible and must represent an erroneous response. Conversely, an example for a faculty to resident ratio greater than 5 would be a program with 5 residents and 25 faculty members. Although the cut-off of 5 is somewhat arbitrary, a faculty ratio of 5 or higher was deemed to be unlikely and possibly caused by an erroneous response. If a resident completed full-time research (i.e. a fellowship, research leave) of $\geq 1$ year duration and of $\geq 3$ to $<12$ month duration, then the response for the $\geq 3$ to $<12$ months research leave were replaced by missing values $(N=13)$. This was done so that the effects of the longer research leave were not attributed to the shorter leave in the statistical analysis.

The respondents included in the analysis had an age of $30.9 \pm 2.8$ years (mean \pm standard deviation) and completed $3.5 \pm 2.0$ years of residency training. Residents enrolled in German programs constituted $64 \%$ of the sample, while residents enrolled in Swiss and Austrian programs constituted $22 \%$ and $14 \%$, respectively. The mean current research activity was $5.2 \pm 7.4 \mathrm{~h} /$ week (detailed sample characteristics are available in Table 1; sample characteristics by country are provided in Supplementary Table 2).

\section{Statistical analyses}

Univariate linear regression was used to determine the association of each of the 30 individual factors (13 modifiable and 17 non-modifiable factors listed in Supplementary Table 1) with the current research activity. The non-modifiable risk factors $(p<0.05)$ identified by the univariate analysis were included in a multivariate regression 
Table 1 Sample characteristics

\begin{tabular}{|c|c|c|}
\hline Characteristic & Sample ${ }^{\S}$ & $N$ \\
\hline \multicolumn{3}{|l|}{ Dependent variable } \\
\hline Current research activity: $\mathrm{h} /$ week & $5.2 \pm 7.42$ & 128 \\
\hline \multicolumn{3}{|l|}{ Modifiable factors } \\
\hline Faculty research output: Likert scale $1-5$ & $3,1-5$ & 128 \\
\hline Faculty research quality: Likert scale $1-5$ & $3,1-5$ & 129 \\
\hline Availability of research infrastructure: Likert scale $1-5$ & $3,1-5$ & 128 \\
\hline Availability of research-related knowledge: Likert scale 1-5 & $2,1-5$ & 129 \\
\hline Availability of research funding: Likert scale $1-5$ & $3,1-5$ & 129 \\
\hline Availability of salary funding: Likert scale $1-5$ & $2,1-5$ & 129 \\
\hline Maximum duration of single employment contract: months & $31.81 \pm 20.42$ & 94 \\
\hline Protected days: days/year & $5.41 \pm 16.32$ & 127 \\
\hline Predictability of protected days on the prior day: $\%$ & $8.11 \pm 21.71$ & 118 \\
\hline Predictability of protected days in the prior week: $\%$ & $6.62 \pm 19.04$ & 120 \\
\hline Support of $\geq 3$ to $<12$ months leave: Likert scale $1-5$ & $2,1-5$ & 127 \\
\hline Support of $\geq 1$ year leave, not counted towards training: Likert scale $1-5$ & $2,1-5$ & 129 \\
\hline Support of $\geq 1$ year leave, counted towards training: Likert scale $1-5$ & $2,1-5$ & 129 \\
\hline \multicolumn{3}{|l|}{ Non-modifiable factors } \\
\hline Completed years of training: years & $3.5 \pm 2.02$ & 126 \\
\hline Age: years & $30.94 \pm 2.82$ & 125 \\
\hline Female gender: no. $(\%)$ & $41,(32 \%)$ & 127 \\
\hline Completion of $\geq 1$ year leave: no. (\%) & $14,(11 \%)$ & 128 \\
\hline Completion of $\geq 3$ to $<12$ months leave: no. (\%) & $16,(14 \%)$ & 115 \\
\hline Employment in Austria: no. (\%) & $18,(14 \%)$ & 129 \\
\hline Employment in Germany: no. (\%) & $82,(64 \%)$ & 129 \\
\hline Employment in Switzerland: no. (\%) & $29,(22 \%)$ & 129 \\
\hline Employment in A-level hospital: no. (\%) & $24,(19 \%)$ & 129 \\
\hline Employment in B-level hospital: no. (\%) & $9,(7 \%)$ & 129 \\
\hline Employment in a University hospital: no. (\%) & $40,(31 \%)$ & 129 \\
\hline Employment in Maximum care hospital: no. (\%) & $19,(15 \%)$ & 129 \\
\hline Employment in a University teaching affiliate: no. (\%) & $15,(12 \%)$ & 129 \\
\hline Employment in privately held institution: no. (\%) & $19,(37 \%)$ & 52 \\
\hline Department size: no. of faculty and residents & $32.31 \pm 18.28$ & 111 \\
\hline Program size: no. of residents & $17.5 \pm 11.43$ & 110 \\
\hline Faculty to resident ratio & $1.05 \pm 0.74$ & 108 \\
\hline
\end{tabular}

${ }^{\S}$ Mean \pm SD for continuous variables; median, range for ordinally scaled variables and number, $(\%$ of $N)$ for binary variable

model to control for these factors. Bonferroni adjustment calculations were performed to account for repeated tests (i.e. for testing 13 modifiable and 17 non-modifiable factors). Associations with $p$ values $<0.05$ were considered significant. To gauge feasibility, an a priori power analysis was performed and a sample size of 53 was determined sufficient to yield a power of 0.80 to detect associations with $R^{2}$ values of 0.25 at an $\alpha$ error probability of 0.0017 (corresponding to 0.05 adjusted for multiple tests of 13 modifiable and 17 non-modifiable factors). The power analysis was performed using $\mathrm{G}^{*}$ Power 3.1 [4]. All other analyses were performed using $\mathrm{R}$ version 3.3.2 (Copyright 2016, The R Foundation, Vienna, Austria).

\section{Results}

Sample characteristics are displayed in Table 1. The univariate analysis identified protected research days $(p<0.001)$, the predictability of protected days in the prior week $(p<0.001)$, the predictability of protected days 1 day previously ( $p<0.001)$, the faculty research output $(p<0.001)$ and quality $(p<0.001)$, the availability 
of research infrastructure $(p<0.001)$, the support of $\mathrm{a} \geq 1$ year research time $(p=0.005)$, and the support of a 3-12 month research time $(p=0.010)$ as significantly associated with increased current research activity. Of the non-modifiable factors, the univariate analysis identified employment in a university hospital $(p<0.001)$, completion of $\geq 1$-year time for research purposes $(p=0.007)$, and department size $(p=0.048)$ as factors associated with increased current research activity. In contrast, employment in Switzerland $(p=0.012)$, female gender $(p=0.016)$, and employment in an A-level hospital $(p=0.024)$ were negatively associated with research activity (Figs. 1, 2; Table 2).

After adjusting for the employment in a universityaffiliated hospital, completion of $\geq 1$ year research time, employment in Switzerland, female gender, employment in an A-level hospital, and department size, as well as a subsequent Bonferroni correction of the $p$ values for 30 tested factors, the multivariate regression analysis identified protected research days $(p=0.029)$, the predictability of protected days in the prior week $(p<0.001)$, and the predictability of protected days on the prior day $(p<0.001)$ as significantly positively associated with increased current research activity (Table 2).

\section{Discussion}

The most important finding of this study was that, as hypothesized, protected research time is associated with a higher self-reported research activity of orthopedic surgery and traumatology residents. Furthermore, the current study demonstrated that advance knowledge of protected research time is positively associated with research activity. This is relevant for programs that have protected research time built into the curriculum as advance notifications are a relatively low-resource change for programs. This study did not confirm the hypotheses that the presence of faculty members who produce high-volume, meaningful research and the presence of robust research infrastructure and funding are associated with the residents' research activity.
Fig. 1 Association of protected days with resident physician's current research activity
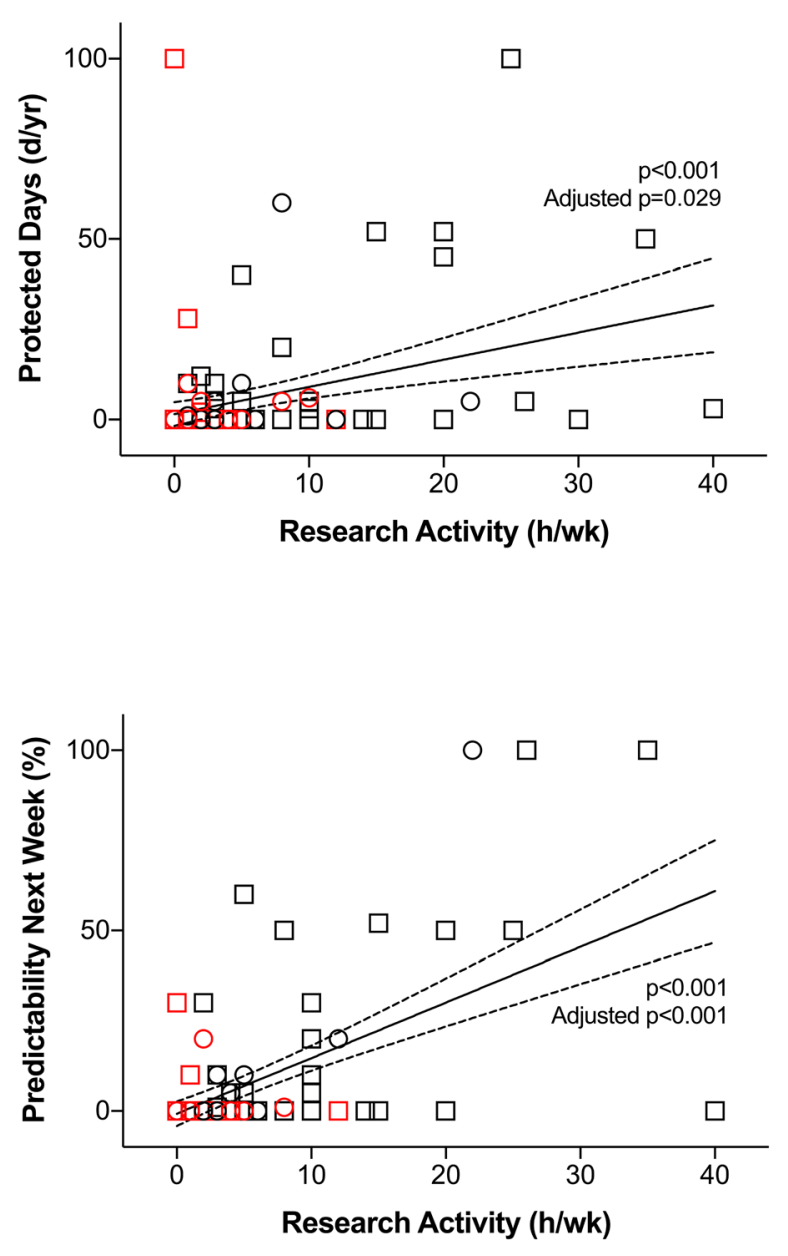

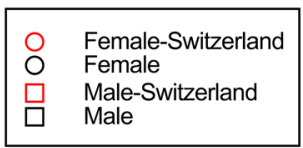
Female Male
Fig. 2 Association of predictability of protected days in the prior week with resident physician's current research activity

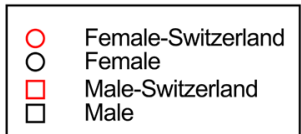
Male 
Table 2 Association with current research activity

\begin{tabular}{|c|c|c|c|c|c|c|c|}
\hline & \multicolumn{3}{|c|}{ Univariate analysis } & \multicolumn{4}{|c|}{ Multivariate analysis ${ }^{\S}$} \\
\hline & $N$ & Coefficient $(95 \% \mathrm{CI})$ & $p$ & $N$ & Coefficient $(95 \% \mathrm{CI})$ & $p$ & Adjusted $p$ \\
\hline \multicolumn{8}{|l|}{ Modifiable factors } \\
\hline $\begin{array}{l}\text { Predictability of protected days in the prior week: } \\
\%\end{array}$ & 120 & $0.22(0.16,0.27)$ & $<0.001$ & 105 & $0.21(0.14,0.28)$ & $<0.001$ & $<0.001$ \\
\hline Predictability of protected days on the prior day: $\%$ & 118 & $0.18(0.13,0.23)$ & $<0.001$ & 103 & $0.16(0.1,0.23)$ & $<0.001$ & $<0.001$ \\
\hline Protected days: days/year & 127 & $0.16(0.08,0.23)$ & $<0.001$ & 110 & $0.13(0.06,0.21)$ & $<0.001$ & 0.029 \\
\hline Faculty research output: Likert scale $1-5$ & 127 & $1.93(0.97,2.9)$ & $<0.001$ & 109 & $1.58(0.43,2.74)$ & 0.009 & n.s. \\
\hline Faculty research quality: Likert scale $1-5$ & 128 & $1.80(0.83,2.76)$ & $<0.001$ & 110 & $1.76(0.6,2.91)$ & 0.004 & n.s. \\
\hline $\begin{array}{l}\text { Availability of research infrastructure: Likert scale } \\
1-5\end{array}$ & 127 & $1.78(0.79,2.76)$ & $<0.001$ & 109 & $1.53(0.29,2.77)$ & 0.017 & n.s. \\
\hline $\begin{array}{l}\text { Support of } \geq 1 \text { year leave, not counted towards } \\
\text { training: Likert scale } 1-5\end{array}$ & 128 & $1.45(0.46,2.44)$ & 0.005 & 110 & $0.42(-0.81,1.64)$ & n.s. & n.s. \\
\hline $\begin{array}{l}\text { Support of } \geq 3 \text { to }<12 \text { months leave: Likert scale } \\
1-5\end{array}$ & 126 & $1.31(0.33,2.29)$ & 0.010 & 108 & $0.88(-0.35,2.12)$ & n.s. & n.s. \\
\hline $\begin{array}{l}\text { Support of } \geq 1 \text { year leave, counted towards train- } \\
\text { ing: Likert scale } 1-5\end{array}$ & 128 & $0.81(-0.37,1.99)$ & n.s. & 110 & $0.57(-0.86,1.99)$ & n.s. & n.s. \\
\hline $\begin{array}{l}\text { Maximum duration of single employment contract: } \\
\text { months }\end{array}$ & 94 & $-0.03(-0.11,0.05)$ & n.s. & 84 & $-0.05(-0.14,0.03)$ & n.s. & n.s. \\
\hline $\begin{array}{l}\text { Availability of research-related knowledge: Likert } \\
\text { scale 1-5 }\end{array}$ & 128 & $0.23(-0.85,1.31)$ & n.s. & 110 & $0.02(-1.29,1.33)$ & n.s. & n.s. \\
\hline Availability of salary funding: Likert scale $1-5$ & 128 & $-0.23(-1.4,0.94)$ & n.s. & 110 & $-0.66(-1.93,0.6)$ & n.s. & n.s. \\
\hline Availability of research funding: Likert scale $1-5$ & 128 & $0.07(-1.06,1.2)$ & n.s. & 110 & $-0.42(-1.73,0.89)$ & n.s. & n.s. \\
\hline \multicolumn{8}{|l|}{ Non-modifiable factors } \\
\hline Employment in a University hospital: yes & 128 & $5.46(2.85,8.08)$ & $<0.001$ & 110 & $3.03(-0.25,6.32)$ & n.s. & n.s. \\
\hline Completion of $\geq 1$ year leave: yes & 127 & $5.62(1.59,9.65)$ & 0.007 & 110 & $4.41(0.25,8.58)$ & 0.040 & n.s. \\
\hline Employment in Switzerland: yes & 128 & $-3.91(-6.91,-0.9)$ & 0.012 & 110 & $-3.33(-9.27,2.61)$ & n.s. & n.s. \\
\hline Female gender: yes & 127 & $-3.37(-6.08,-0.65)$ & 0.016 & 110 & $-2.82(-5.78,0.15)$ & n.s. & n.s. \\
\hline Employment in A-level hospital: yes & 128 & $-3.78(-7.02,-0.54)$ & 0.024 & 110 & $-0.71(-7.14,5.72)$ & n.s. & n.s. \\
\hline Department size: no. of faculty and residents & 111 & $0.08(0,0.16)$ & 0.048 & 110 & $0.07(-0.01,0.15)$ & n.s. & n.s. \\
\hline Employment in Germany: yes & 128 & $2.44(-0.21,5.1)$ & n.s. & 110 & $-0.47(-4.62,3.68)$ & n.s. & n.s. \\
\hline Completion of $\geq 3$ to $<12$ months leave: yes & 114 & $3.18(-0.3,6.66)$ & n.s. & 96 & $3.44(-0.29,7.16)$ & n.s. & n.s. \\
\hline Program size: no. of residents & 110 & $0.11(-0.01,0.24)$ & n.s. & 108 & $0.08(-0.18,0.34)$ & n.s. & n.s. \\
\hline Employment in B-level hospital: yes & 128 & $-3.56(-8.56,1.45)$ & n.s. & 110 & $-0.51(-9.28,8.26)$ & n.s. & n.s. \\
\hline Age: years & 125 & $-0.25(-0.71,0.22)$ & n.s. & 109 & $-0.33(-0.83,0.16)$ & n.s. & n.s. \\
\hline Employment in a University teaching affiliate: yes & 128 & $2.04(-1.95,6.04)$ & n.s. & 110 & $3.65(-0.86,8.16)$ & n.s. & n.s. \\
\hline Employment in Maximum care hospital: yes & 128 & $-1.84(-5.45,1.78)$ & n.s. & 110 & $-3.40(-7.26,0.46)$ & n.s. & n.s. \\
\hline Faculty to resident ratio & 108 & $0.74(-1.26,2.75)$ & n.s. & 107 & $0.48(-1.38,2.34)$ & n.s. & n.s. \\
\hline Employment in Austria: yes & 128 & $1.06(-2.73,4.86)$ & n.s. & 110 & $0.47(-3.68,4.62)$ & n.s. & n.s. \\
\hline Completed years of training: years & 126 & $-0.16(-0.81,0.49)$ & n.s. & 109 & $-0.23(-0.91,0.45)$ & n.s. & n.s. \\
\hline Employment in privately held institution: yes & 51 & $-0.47(-2.78,1.85)$ & n.s. & 41 & $-0.72(-3.81,2.38)$ & n.s. & n.s. \\
\hline
\end{tabular}

n.s. not significant

$\S$ Adjusted for employment in a University hospital, completion of $\geq 1$ year leave, employment in Switzerland, female gender, employment in A-level hospital, and department size

In the univariate analysis, this study further highlights that research activity is influenced by factors that cannot be changed by the program leadership, such as the geography, type of hospital, and other intrinsic factors to the program. Adjusted for such factors, in the multivariate analysis, one additional protected day per week is estimated to increase research activity by $\sim 7 \mathrm{~h}$ per week ( $95 \%$ confidence interval of $\sim 3$ to $\sim 11 \mathrm{~h}$ per week). Prior work of others supports that the available time is the major factor determining research activity. Al-Taha et al. [2] showed that the top perceived barrier to conducting research was the lack of time (83\%) amongst Canadian plastic surgery residents participating in 
a national multicenter cross-sectional study. Levy et al. [7] showed an increase in publications by non-board certified surgeons, as well as an increase in resident first-authorship following the institution of the 80-h workweek limit in 2002. Williams et al. [11] came to the same conclusion. In contrast to these findings, Krueger et al. [6] investigated three different orthopedic residency programs: (1) had a mandatory research year for all residents, (2) had an elective research year for one resident, (3) had no dedicated research time for residents. Interestingly, the research programs with dedicated research time did not produce significantly more or higher quality publications. The authors concluded that research output may be more related to staff engagement, intrinsic motivation for research, and the availability of mentorship programs for the residents. These findings also confirm the results from Osborn et al. [8] with no difference in research output and dedicated research time, but a significantly higher output by faculty with more than 10 years of experience. Of note, Levy et al. [7] and Williams et al. [11] had more residents included in their study compared to Krueger et al. [6], which may indicate a lack of power in the latter study.

A more concerning publication by Grova et al. [5] found a significant decline of self-reported surgical skills and clinical aptitude in residents who spent a year or longer of dedicated research time. They concluded that their findings may have a dramatic effect on the confidence of residents in their further clinical career. This has also been shown by D'Angelo et al. [3], who proposed that the use of simulation might maintain procedural skills and confidence in residents pursuing dedicated research time. Thus, when implementing strategies to motivate residents for research, it is important to implement measures to maintain clinical and surgical skills. This may implicate a structured research program to make sure that clinical performance will not suffer from dedicated research time.

In addition to providing more protected time, the current study highlights the importance of advance scheduling. The study indicates that if scheduling can be improved such that a resident has advance knowledge ( $>1$ week) of a research day for half, instead of a quarter of these occurrences the resident's research activity increases by approximately $5 \mathrm{~h}$ per week ( $\sim 4$ to $\sim 7 \mathrm{~h}$ per week). This increase is without providing any additional protected days. Although not significant after adjusting for multiple tests, residents who completed a dedicated research year are estimated to perform approximately $4 \mathrm{~h}$ more research per week ( $\sim-9 \mathrm{~h}$ per week) than residents who did not. While there may be an effect of a dedicated research year on subsequent research activity, this study suggests that providing plannable protected days throughout the residency training is more strongly related to resident's research activity and may be a more effective measure than supporting a dedicated research year.
After lack of time, the second most commonly perceived barrier to research amongst the plastic surgery residents surveyed by Al-Taha et al. [2] was a lack of research supervisors and mentors. Though not significant in our study after controlling for non-modifiable factors and adjusting for multiple tests, there may be an association between the faculty's research output and quality and the resident's research activity. Residents' who agree with the statement that the attending surgeons at their institution perform highquality research are estimated to engage in approximately $4 \mathrm{~h}(\sim 1-6 \mathrm{~h})$ more research per week than residents who disagree. Sufficiently powered additional research is needed to confirm this association. A complex research ethics/institutional review process has been previously described as a frequently perceived barrier [2], but was not included in our questionnaire. Developing a faculty with high research quality and output that can provide supervision and mentoring may be an effective measure to increase resident physicians' research activity.

While this study focuses on the identification of modifiable factors associated with residents' research activity, this study further highlights that research activity may be influenced by factors that cannot be changed by the program leadership. Of note, in the univariate analysis, residents in Switzerland are estimated to spend $\sim 4 \mathrm{~h}$ less on research per week (95\% confidence interval of $\sim 1-7 \mathrm{~h}$ per week) than residents outside of Switzerland. However, this finding is not statistically significant after correcting for the testing of multiple hypotheses and sufficiently powered additional research is needed to confirm this association. Swiss programs did not differ significantly in the predictability and number of protected days, and their residents even reported a somewhat increased perceived availability of researchrelated knowledge, funding, and support to spend $\geq 1$ year of dedicated research time (Supplementary Table 2). Notably, the maximum duration of employment contracts are estimated to be of $\sim 11$ months shorter duration in Swiss programs ( 1-20 months) for an average of 23 months (Supplementary Table 2). However, the maximum employment contract duration was not significantly associated with the residents' research activity (Table 2). This current study did not identify organizational differences or other factors that could explain a potentially reduced research activity amongst residents in Swiss programs.

In addition to the factors included in this study, orthopedic and trauma surgery residency programs are also affected by broad societal and generational changes [10]. These changes may also be important determinants of research interest and productivity during residency training.

The study sample only represents a small fraction of the orthopedic surgery and traumatology residents across Austria, Switzerland, and Germany. Although the total number of residents is not publicly available, we identified 
796 programs with university-hospital affiliation that we have contacted and received responses from 129 residents that were included in the analysis. The inability to contact residents directly likely contributed to the relatively low response rate. Thus, our findings might not be applicable to all programs, but should apply to all programs that disseminated our invitation to their residents. The latter programs are considered much more likely to make use of the reported data, which mitigates this limitation to some degree. The relatively low response rate could also be due to a low interest amongst residents in pursuing research. The availability of pertinent data is limited, but Ahn et al. found amongst U.S. orthopedic surgery residents that interest is quite high, with only $30 \%$ of residents being uninterested in performing research. In addition, this rate was not different between survey responders and non-responders [1]. However, data on research interest amongst European orthopedic surgery residents are not available, and it would be prudent to assume that respondents to our survey had a higher than average interest in performing research. Thus, our findings may only apply to programs with residents that show a prior interest in performing research. The study design, including the adjustment for substantial non-modifiable factors and a strict correction for multiple hypothesis testing, was primarily geared towards identifying those modifiable factors with a strong association to the resident's research activity. It is, however, limited in demonstrating the absence of an association and factors without significant association may still have a substantial effect. Furthermore, the self-reported time spent on research in hours per week as a dependent variable has been chosen. While hours per week is a meaningful variable to gauge a resident's current research activity, it is not a direct measure of research output. As it does provide a more granular metric for research activity compared to the number of publications, given that the time spent on each publication can vary widely, it was selected as most suitable measure for this investigation. Information on whether and to which extent research activity is performed during as opposed to outside of regular working hours was not obtained in this study but may be an important factor associated with residents' research activity.

\section{Conclusion}

As hypothesized, protected research days and, perhaps more importantly, predictable protected research days are significantly associated with more research activity in orthopedic surgery and traumatology resident physicians. In contrast, hypotheses that the presence of faculty members who produce high-volume, meaningful research and the presence of robust research infrastructure and funding are associated with the residents' research activity were not confirmed. Therefore, program directors and department chairs seeking to promote research activity should focus on creating plannable protected time for research.

Acknowledgements Open Access funding provided by Projekt DEAL. We would like to thank all members of the Society of Arthroscopy and Joint Surgery (AGA) Residents Forum Research Working Group including Claudia Hartz, Martin Hufeland, Alexander Zimmerer, Christine Haberer, Christian Holwein, Philipp Dworschak, Matthias Rüschenschmidt, Daniel Jan Rzepka, and Sebastian Gebhardt for their contributions to developing the study's objective and approach. We also want to thank Michael Hirschmann for his guidance.

Funding The study has been supported by direct funding from the German-speaking Society for Arthroscopy and Joint Surgery (AGA). The organization had no influence on study design, data collection or interpretation of the results or the final manuscript.

\section{Compliance with ethical standards}

Conflict of interest All authors were orthopedic residents with an affinity for research when this study was conducted.

Ethical approval The investigation did not involve identifiable private information and was thus considered exempt from ethical review according to the Professional Code for Physicians of Bavaria (Bavarian Chamber of Physicians).

Open Access This article is licensed under a Creative Commons Attribution 4.0 International License, which permits use, sharing, adaptation, distribution and reproduction in any medium or format, as long as you give appropriate credit to the original author(s) and the source, provide a link to the Creative Commons licence, and indicate if changes were made. The images or other third party material in this article are included in the article's Creative Commons licence, unless indicated otherwise in a credit line to the material. If material is not included in the article's Creative Commons licence and your intended use is not permitted by statutory regulation or exceeds the permitted use, you will need to obtain permission directly from the copyright holder. To view a copy of this licence, visit http://creativecommons.org/licenses/by/4.0/.

\section{References}

1. Ahn J, Donegan DJ, Lawrence JT, Halpern SD, Mehta S (2010) The future of the orthopaedic clinician-scientist: part II: identification of factors that may influence orthopaedic residents' intent to perform research. J Bone Joint Surg Am 92:1041-1046

2. Canadian Plastic Surgery Research Collaborative (2017) Barriers and attitudes to research among residents in plastic and reconstructive surgery: a national multicenter cross-sectional study. J Surg Educ 74:1094-1104

3. D’Angelo AL, Ray RD, Jenewein CG, Jones GF, Pugh CM (2015) Residents' perception of skill decay during dedicated research time. J Surg Res 199:23-31

4. Faul F, Erdfelder E, Buchner A, Lang AG (2009) Statistical power analyses using $G^{*}$ Power 3.1: tests for correlation and regression analyses. Behav Res Methods 41:1149-1160

5. Grova MM, Yang AD, Humphries MD, Galante JM, Salcedo ES (2017) Dedicated research time during surgery residency leads to a significant decline in self-assessed clinical aptitude and surgical skills. J Surg Educ 74:980-985 
6. Krueger CA, Hoffman JD, Balazs GC, Johnson AE, Potter BK, Belmont PJ Jr (2017) Protected resident research time does not increase the quantity or quality of residency program research publications: a comparison of 3 orthopedic residencies. J Surg Educ 74:264-270

7. Levy DM, Luchetti TJ, Levine BR (2017) Have residents produced more research since the inception of the 80-hour workweek? Iowa Orthop J 37:205-209

8. Osborn PM, Ames SE, Turner NS, Caird MS, Karam MD, Mormino MA et al (2018) An analysis of research quality and productivity at six academic orthopaedic residencies. J Surg Educ 75:1635-1642

9. Robbins L, Bostrom M, Marx R, Roberts T, Sculco TP (2013) Restructuring the orthopedic resident research curriculum to increase scholarly activity. J Grad Med Educ 5:646-651
10. Seil R (2019) Why ESSKA? On what it takes for orthopaedic surgeons and their scientific societies to adapt to societal changes in 2018. Knee Surg Sports Traumatol Arthrosc 27:665-672

11. Williams BR, Agel JA, Van Heest AE (2017) Protected time for research during orthopaedic residency correlates with an increased number of resident publications. J Bone Joint Surg Am 99:e73

Publisher's Note Springer Nature remains neutral with regard to jurisdictional claims in published maps and institutional affiliations.

\section{Affiliations}

\section{Andreas Voss ${ }^{1,2,3}$ - Björn Andre ${ }^{4} \cdot$ Leo Pauzenberger $^{5} \cdot$ Elmar Herbst $^{3,6} \cdot$ Jonas Pogorzelski $^{3} \cdot$ Dominik John $^{7}$. Daniel Smolen ${ }^{8,9}$. Philip P. Roessler ${ }^{10}$. Daniel G. Tobert ${ }^{11}$ - Jakob T. Sieker ${ }^{12,13}$ (D) For the Society of Arthroscopy and Joint Surgery (AGA) Residents Forum, Research Working Group}

1 Department of Trauma Surgery, University Medical Center Regensburg, Franz-Josef-Strauß-Allee 11, 93053 Regensburg, Germany

2 Sporthopaedicum Straubing-Regensburg, Regensburg, Germany

3 Department of Orthopaedic Sports Medicine, Technical University of Munich, Munich, Germany

4 Department of Orthopedic Surgery, Catholic Clinics Koblenz-Montabaur, Koblenz, Germany

5 Sports Surgery Clinic, Dublin, Ireland

6 Department of Trauma, Hand and Reconstructive Surgery, University Hospital Münster, Münster, Germany

7 West German Knee and Shoulder Center, Cologne, Germany
8 Shoulder and Elbow Department, Alphaclinic, Zurich, Switzerland

9 Ludwig Boltzmann Institute (LBI) for Experimental and Clinical Traumatology, Vienna, Austria

10 Department of Orthopedics and Trauma Surgery, University Hospital Bonn, Bonn, Germany

11 Department of Orthopedic Surgery, Massachusetts General Hospital, Boston, MA, USA

12 Department of Orthopedic Surgery, Boston Children's Hospital, Harvard Medical School, Boston, MA, USA

13 Department of Pathology and Laboratory Medicine, Tufts Medical Center, Tufts University School of Medicine, Boston, MA, USA 